\title{
Sciendo
}

\author{
RESEARCH PAPERS FACULTY OF MATERIALS \\ SCIENCE AND TECHNOLOGY IN TRNAVA \\ SLOVAK UNIVERSITY OF TECHNOLOGY \\ IN BRATISLAVA
}

2019, Volume 27, Number 44

DOI 10.2478/rput-2019-0004

\section{IMPACT OF SELECTED ELECTRICAL CABLES SLOPE ON FLAME OUT TIME AND FLAME SPREAD}

\author{
Aleš NEČAS ${ }^{1 *}$, Jozef MARTINKA ${ }^{1}$, Igor WACHTER ${ }^{1}$, Tomáš ŠTEFKO ${ }^{1}$, \\ Martina HLADOVÁ ${ }^{1}$, Denis BENKO ${ }^{1}$, Karol BALOG ${ }^{1}$, Libor ŠEVČÍIK $^{2}$ \\ ${ }^{1}$ SLOVAK UNIVERSITY OF TECHNOLOGY IN BRATISLAVA, \\ FACULTY OF MATERIALS SCIENCE AND TECHNOLOGY IN TRNAVA, \\ INSTITUTE OF INTEGRATED SAFETY, \\ Ulica JÁna BotTu 2781/25, 91724 TRNAVA, SLOVAKIA

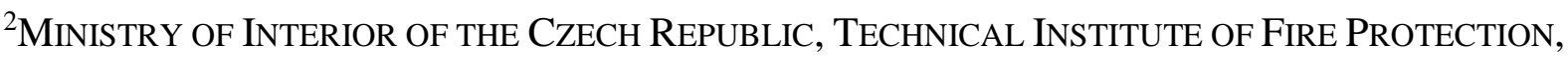 \\ Písková 42, 143 00, Prague 4, Czech Republic \\ e-mail: ales.necas@stuba.sk,jozef.martinka@stuba.sk,igor.wachter@stuba.sk, \\ tomas.stefko@stuba.sk,martina.hladova@stuba.sk,xbenkod@stuba.sk, \\ karol.balog@stuba.sk, libor.sevcik@tupo.izscr.cz \\ Received: 24.04.2019, Accepted: 18,06,2019, Published: 25.07.2019
}

\begin{abstract}
The aim of the research described in this paper was to study the impact of the electrical cables slope on the flame out time and the flame spread rate. Measured cables were thermally loaded by methanol flame (diameter of the container was $106 \mathrm{~mm}$ ) at seven different slopes with respect to the horizontal plane (the slopes were $0^{\circ}$ - horizontal orientation, $15^{\circ}, 30^{\circ}$, $45^{\circ}, 60^{\circ}, 75^{\circ}$ and $90^{\circ}$ - vertical orientation). The first tested electrical cable was a copper three-core power one resistant to the flame spread with circuit integrity of the cable system during 30 minutes under fire (cross-section of each core was $1.5 \mathrm{~mm}^{2}$ ). The second tested electrical cable was a copper two-core signal one resistant to the flame spread with circuit integrity of the cable system during 30 minutes under fire (cross-section of each core was 0.5 $\mathrm{mm}^{2}$ ). The first electrical cable did not show reaction to fire class. The reaction to fire class of the second tested cable was $B 2_{c a}, s 1, d 1$, al. The obtained results proved that slope had virtually no impact on the flame out time and the flame spread over the tested cable surface (tested cables of all slopes stopped burning after 1 to 5 seconds after methanol flame burned out). Likewise, the flame spread was only negligibly beyond the border of flame action for each cable slope.
\end{abstract}

\section{Key words}

Electrical cable, ignition, flame spread, flame out time, safety 


\section{INTRODUCTION}

The rate of flame spread over the surface of an electrical cable is an important fire feature that expresses the capability of an electrical cable to spread flame on its surface. In accordance with applicable laws (e.g. the Slovak Republic Decree of the Ministry of Interior No. 94/2004 Collection of Laws [1]) the cable routes and cable ducts must be sealed when passing through the fire compartment structures. Therefore, the flame spread rate on the surface of the electrical cables does not reflect the capability of the electrical cable to extend the fire outside the fire compartment, but only the capability to spread fire (to contribute to the development of fire) within the fire compartment. Flame propagation is an important input for classifying electrical cables in reaction to fire classes $\mathrm{B} 1_{\mathrm{ca}}, \mathrm{B} 2_{\mathrm{ca}}, \mathrm{C}_{\mathrm{ca}}, \mathrm{D}_{\mathrm{ca}}$ and $\mathrm{E}_{\mathrm{ca}}$. For classification into reaction to fire classes from $\mathrm{B} 1_{\mathrm{ca}}$ to $\mathrm{E}_{\mathrm{ca}}$ the electrical cable must meet the requirements of EN 13501-6:2018 [2] for limited vertical flame spread according to IEC 60332-1-2:2004 [3] and at the same time for classification into reaction to fire classes from $\mathrm{B} 1_{\mathrm{ca}}$ to $\mathrm{C}_{\mathrm{ca}}$, the electrical cable (among other things) must meet the restricted flame spreading requirements according to EN 50399:2011/A1:2016 [4]. Flame propagation in tests according to the cited IEC and EN standards [3-4] is determined only in vertical direction (for vertical orientation of the electrical cable). Power output, orientation and other parameters as well as ignition conditions are also defined in the cited IEC and EN standards [3-4]. However, the ignition and propagation of the flame on the surface of the electrical cables depends on a large amount of external conditions, in particular the orientation of the electrical cable and the parameters of the ignition source (the arrangement of the electrical cables also has a significant influence). The arrangement influence of the cables on the fire characteristics was investigated by e.g. Huang et al. [5]. The influence of other factors on fire characteristics and the spread of flame on the surface of electrical cables were investigated in scientific work of Zavaleta et al. [6] and Sarazin et al. [7]. Considerably less attention has been dedicated to researching the influence of an electrical cable slope (relative to the horizontal plane) on the flame out time and the spread of flame over the surface.

The aim of this paper is to determine the influence of the slope of two selected electrical cables (three-core power cable and two-core signal cable) on the flame out time and spread of flame over the surface.

\section{MATERIALS AND METHODOLOGY OF EXPERIMENT}

Two electrical cables were investigated. The first electrical cable labeled CHKE-V J3 1.5 E30 (hereinafter referred to as CHKE-V) was manufactured and supplied by the VUKI, a.s., Slovakia. It is a three-core power cable resistant to flame spread. The cores are made from bar copper, each with the cross-section of $1.5 \mathrm{~mm}^{2}$. The cable shows circuit integrity of cable system under fire during 30 minutes. The reaction to fire class of CHKE-V cable was not declared by the manufacturer. Rated voltage of CHKE-V cable is $1000 \mathrm{~V}$ DC (direct current) and $600 \mathrm{~V} \mathrm{AC}$ (alternating current). The second electrical cable marked JE-H(St)H $1 \times 2 \times 0.8$ PS30 (hereinafter referred to as $\mathrm{JE}-\mathrm{H}(\mathrm{St}) \mathrm{H}$ ) was manufactured and supplied by the VUKI, a.s., Slovakia. It is a two-core signal shielded cable with declared reaction to the fire class of $\mathrm{B} 2_{\mathrm{ca}}(\mathrm{s} 1, \mathrm{~d} 1, \mathrm{a} 1)$ resistant to flame spread. The cores are made from a copper bar, each with the cross-section of $0.5 \mathrm{~mm}^{2}$. The insulated cores are wrapped by a glass mica tape and shielded by an aluminium foil with a drain wire. This cable shows circuit integrity of a cable system under fire during 30 minutes. Rated voltage of $\mathrm{JE}-\mathrm{H}(\mathrm{St}) \mathrm{H}$ is $225 \mathrm{~V}$ (both AC and DC).

The tested electrical cables are shown in Fig. 1. The mass of the base components constituting the tested electrical cables (per unit length) is illustrated in Fig. 2. 
The influence of the cable slope on the ignition and propagation of the flame was determined using a device shown in Fig. 3. The test device (Fig. 3) allowed the tilt of the test cable to be adjusted steadily from $0{ }^{\circ}$ to $90^{\circ}$ by changing the height of the stand with adjustable height (Fig. 3). Experiments were performed at seven different slopes $\left(0^{\circ}\right.$ horizontal orientation, $15^{\circ}, 30^{\circ}, 45^{\circ}, 60^{\circ}, 75^{\circ}$ and $90^{\circ}$ - vertical orientation). As the initiator, methanol was used and burned in a steel container with a diameter of $106 \mathrm{~mm}$, a height of 20 $\mathrm{mm}$ (wall thickness $2 \mathrm{~mm}$ ). The methanol vessel was placed approximately $8 \pm 2 \mathrm{~cm}$ below the test cable during the experiment. The cable was exposed to flame until the methanol was completely burned out in the vessel ( $12 \pm 0.5$ minutes $)$. The average burning rate of methanol was $11.2 \mathrm{~g} / \mathrm{min}$. The calorific value of methanol according to Hynes [8] is $20.1 \mathrm{MJ} / \mathrm{kg}$ and the heat release rate of methanol (burning in a vessel with parameters identical to that used in the experiment) according to Martinka [9] is in the range of 200 to $300 \mathrm{~kW} / \mathrm{m}^{2}$ (total power output of the burner was from 1.76 to $2.64 \mathrm{~kW}$ ).

The main criterion for evaluating the slope influence of the of the tested cables on flame out time and flame spread was the flame out time of the cable after the methanol was completely burned out and the maximum distance the flame spread across the cable surface from the methanol flame point.

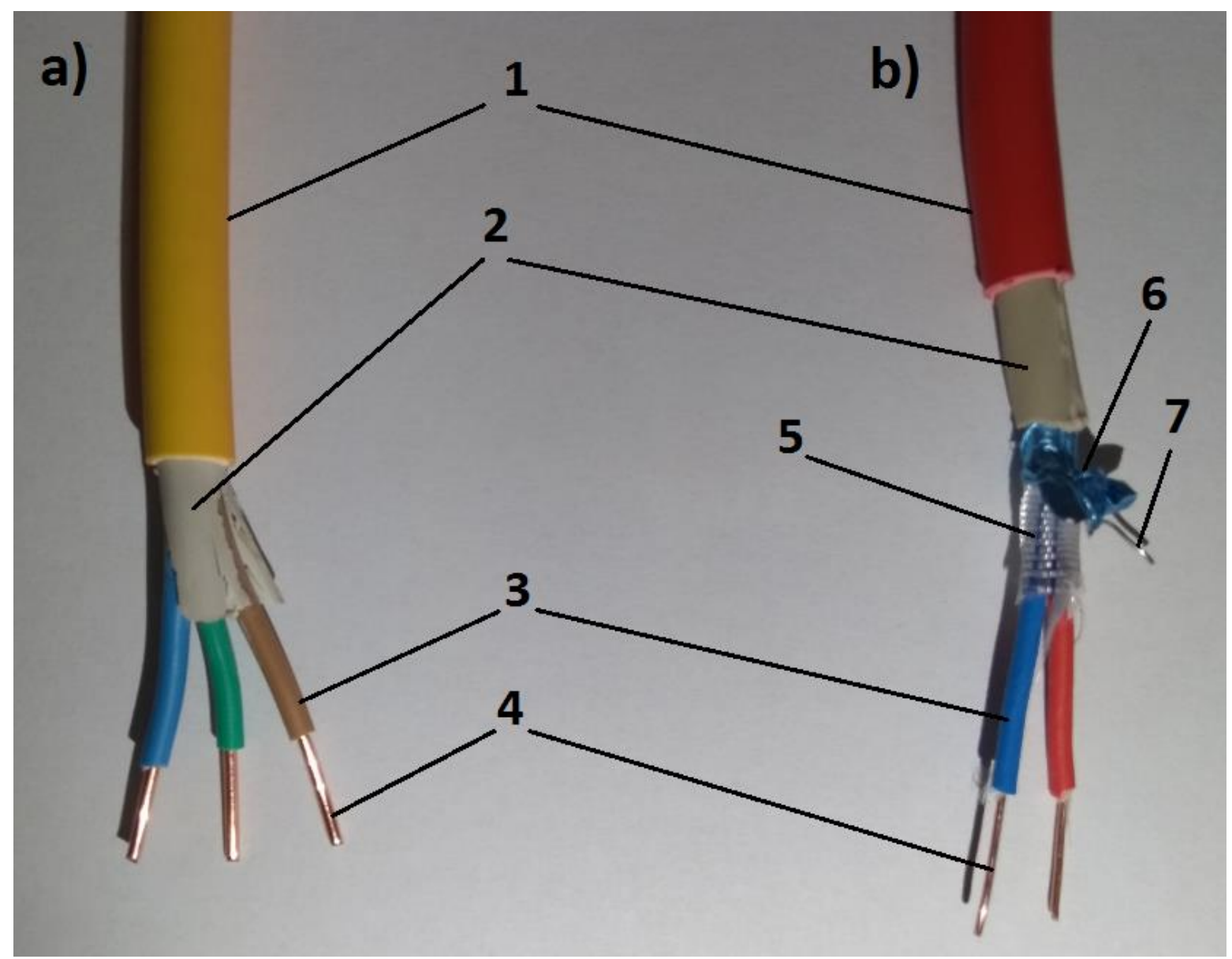

1: Sheath, 2: bedding, 3: insulation, 4: bar copper wire, 5: glass mica tape, 6: aluminium shield foil, 7: drain wire.

Fig. 1 Photo of tested electrical cables a) CHKE-V, b) JE-H(St)H 


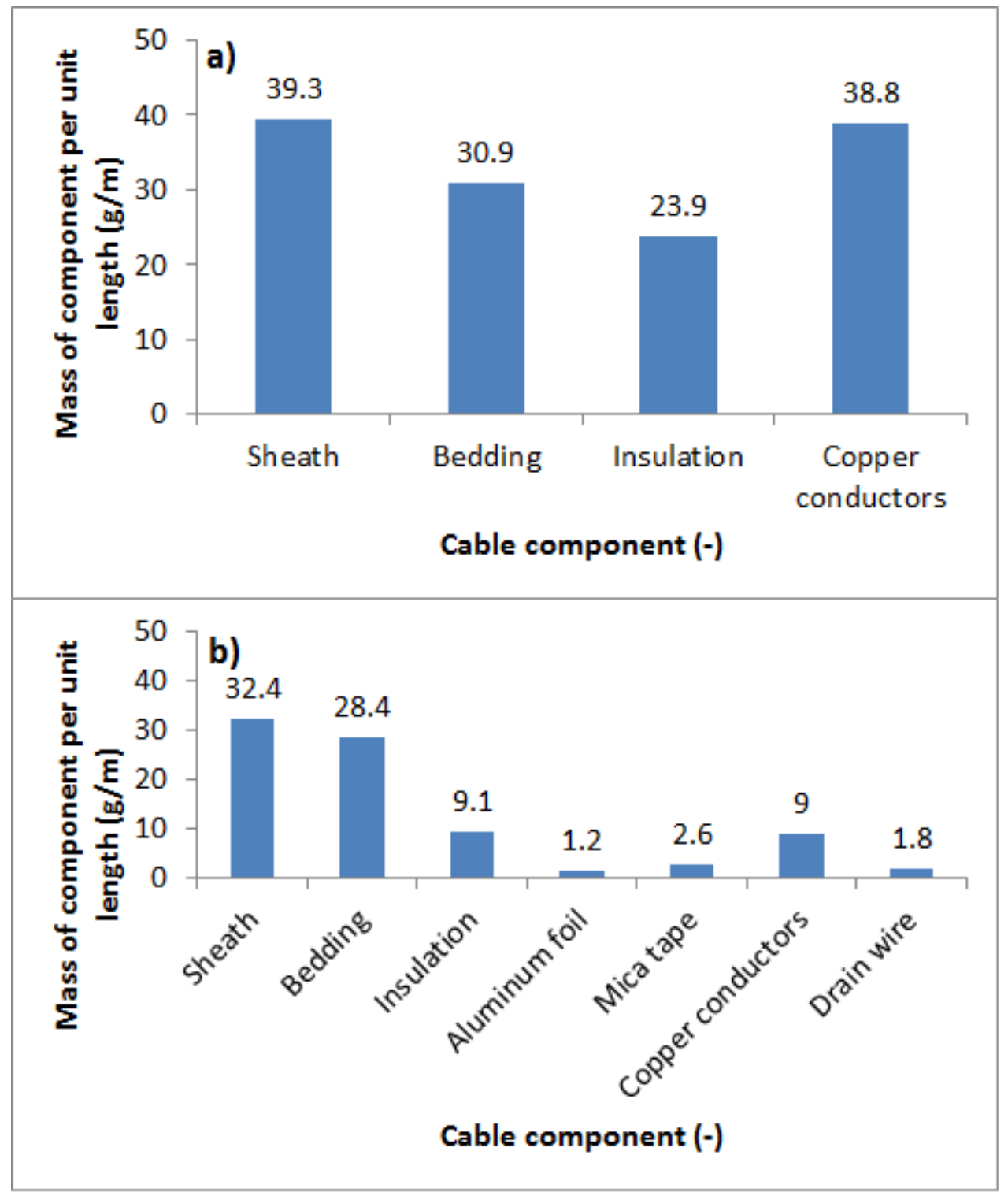

Fig. 2 Mass of basic components of tested electrical cables per unit length a) CHKE-V, b) $J E-H(S t) H$ 
a)

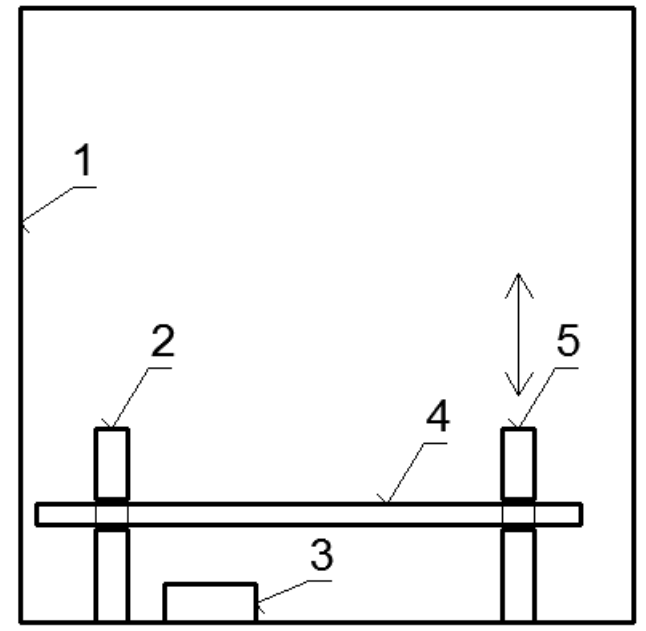

b)

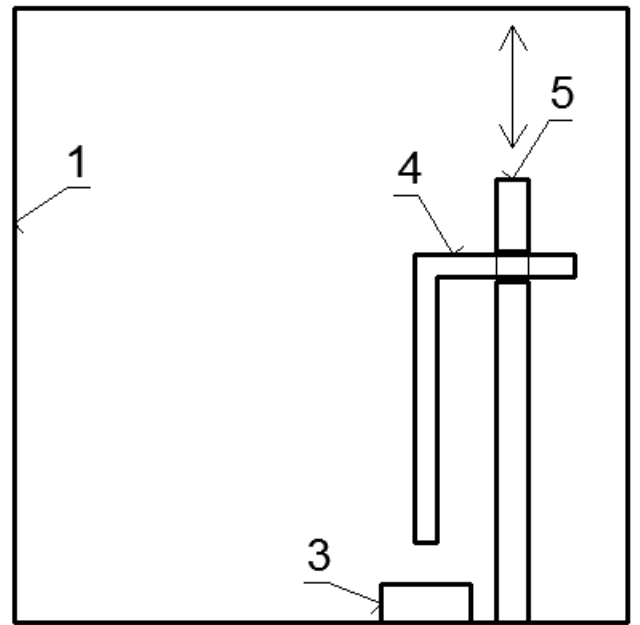

1: Measuring chamber, 2: fixed stand, 3: burner (container of methanol),

4: tested electrical cable, 5: adjustable height stand.

Fig. 3 Measuring device a) for experiments with cables slope from 0 to $75^{\circ}$,

b) for experiments with cables slope of $90^{\circ}$

\section{RESULTS AND DISCUSSION ON RESULTS}

Dependence of flame out time (after methanol burn out) of the tested cables and flame spread over surface on the tested cables slope with respect to the horizontal plane is illustrated in Table 1 (CHKE-V cable) and Table 2 (JE-H(St)H cable).

Table 1 Flame out time and flame spread over CHKE-V cable for tested samples slope

\begin{tabular}{|l|l|l|l|l|l|l|l|}
\hline Slope $\left(^{\circ}\right)$ & $\mathbf{0}$ & $\mathbf{1 5}$ & $\mathbf{3 0}$ & $\mathbf{4 5}$ & $\mathbf{6 0}$ & $\mathbf{7 5}$ & $\mathbf{9 0}$ \\
\hline Flame out time (s) & $<5$ & $<5$ & $<5$ & $<5$ & $<5$ & $<5$ & $<5$ \\
\hline Flame spread (mm) & $<20$ & $<20$ & $<20$ & $<20$ & $<20$ & $<20$ & 120 \\
\hline
\end{tabular}

Table 2 Flame out time and flame spread over JE-H(St)H cable for tested samples slope

\begin{tabular}{|l|l|l|l|l|l|l|l|}
\hline Slope $\left(^{\circ}\right)$ & $\mathbf{0}$ & $\mathbf{1 5}$ & $\mathbf{3 0}$ & $\mathbf{4 5}$ & $\mathbf{6 0}$ & $\mathbf{7 5}$ & $\mathbf{9 0}$ \\
\hline Flame out time (s) & $<5$ & $<5$ & $<5$ & $<5$ & $<5$ & $<5$ & $<5$ \\
\hline Flame spread (mm) & $<20$ & $<20$ & $<20$ & $<20$ & $<20$ & $<20$ & 80 \\
\hline
\end{tabular}


The data in Tables 1 and 2 show that the slope of the tested electrical cables in the range of $0^{\circ}$ to $90^{\circ}$ had virtually no effect on the flame out time after flame out of ignition burner (methanol) since the 5 second time variance was negligible in practical terms. The data in Tables 1 and 2 also show that the slope of the tested electrical cables in the $0^{\circ}$ to $75^{\circ}$ range had virtually no effect on the flame spread over its surface. At a $90^{\circ}$ slope, the CHKE-V electrical cable extended the flame from the lower edge by approx. $120 \mathrm{~mm}$ and an electrical cable JE-H (St) $\mathrm{H}$ extended the flame from the lower edge by approx. $80 \mathrm{~mm}$. Part of the reason is the fact that at a slope of $90^{\circ}$ the flame of the ignition burner did not only affect the test cable sheath but also its cross section (Fig. 3b). However, even at a $90^{\circ}$ slope, the flame only spread to a distance approximately equivalent to that of the cable directly exposed to the flame.

Different conclusions were reported by Chen et al. [10], Beji et al. [11], Hu et al. [12] and Morandini et al. [13] according to which the spread of flame over the surface of electrical cables (but also other materials) depends on their slope and other conditions (e.g. air pressure). The reason of these different conclusions was the fact that the electrical cables resistant to flame spread were investigated in this scientific paper, while electrical cables (and other materials) that were not resistant to flame spread were investigated in the cited scientific papers [10-13]. The cause of the resistance of the tested cables to flame spread was the high content of inorganic fillers (especially aluminum hydroxide and calcium carbonate) in the sheath and bedding, while aluminum hydroxide has been endothermic decomposed to the aluminum oxide and water and the calcium carbonate was endothermic decomposed to calcium oxide and carbon dioxide. The CHKE-V electrical cable formed a charred layer on its surface during the test, which did not burn further when the initiating burner burned out. Also, the electrical cable JE-H (St) $\mathrm{H}$ formed a carbonized layer on its surface during the test, to a lesser extent, however. After the sheath and bedding had been burned, the other polymer components (copper wire insulation) of the $\mathrm{JE}-\mathrm{H}(\mathrm{St}) \mathrm{H}$ electrical cable were protected by an aluminum shielding foil and glass-talc tape (Fig. 1a), which was also a partial reason why this cable did not spread flames over its surface.

\section{CONCLUSION}

In the research described in this paper, the influence of the slope of two electrical cables (with declared flame spread resistance by the manufacturer) on flame out time and on the spread of flame over the surface was investigated. The aim of the research was to determine whether, in electrical cables with declared flame spread resistance, flame out time and flame spread depend on their slope. The obtained results prove that in the slope of the tested electrical cables against the horizontal plane from 0 to $90^{\circ}$, the flame out time was practically independent of the electrical cable slope. In the slope range from 0 to $75^{\circ}$, the slope of the tested electrical cables had virtually no effect on the flame spread over its surface. Tested cables with $90^{\circ}$ slope spread the flame by $80 \mathrm{~mm}($ cable JE-H(St)H) or $120 \mathrm{~mm}(\mathrm{CHKE}-\mathrm{V}$ cable) from the bottom of the cable. Partial reason was the fact that at a $90^{\circ}$ slope, the flame did not only affect the shell but also the entire cable cross-section (however, even in this orientation, only part of the cable directly exposed to the flame burned down). Thus, even at $90^{\circ}$ inclination, the tested electrical cables behaved as resistant to flame spread. Therefore, the slope of the tested electrical cables does not affect the flame out time and the flame spread over the surface (under similar conditions to those described in this experiment).

\section{Acknowledgement}

This research output was supported by the Slovak Research and Development Agency under the contract No. APVV-16-0223. 


\section{References}

[1] DECREE of the Ministry of Interior of SR n. 94/2004 Collection of Laws, on the Technical Requirements for Fire Safety during Construction and Use of Buildings.

[2] EN 13501-6:2018. 2018. Fire classification of construction products and building elements. Part 6: Classification using data from reaction to fire tests on power, control and communication cables. Brussels: European Committee for Standardization, $32 \mathrm{p}$.

[3] IEC 60332-1-2:2004. 2004. Tests on electric and optical fibre cables under fire conditions - Part 1-2: Test for vertical flame propagation for a single insulated wire or cable-Procedure for $1 \mathrm{~kW}$ pre-mixed flame. 1st ed. Geneva: International Electrotechnical Commission, $21 \mathrm{p}$.

[4] EN 50399:2011/A1:2016. 2016. Common test methods for cables under fire conditions. Heat release and smoke production measurement on cables during flame spread test. Test apparatus, procedures, results. Brussels: European Committee for Standardization, $62 \mathrm{p}$.

[5] HUANG, X., ZHU, H., PENG, L., ZHENG, Z., ZENG, W., BI, K., CHENG, C., CHOW, W. 2019. Burning behavior of cable tray located on a wall with different cable arrangements. Fire and Materials, 43(1), 64-73. ISSN 0308-0501.

[6] ZAVALETA, P., SUARD, S., AUDOUIN, L. 2018. Fire spread from an open-doors electrical cabinet to neighboring targets in a confined and mechanically ventilated facility. Fire and Materials, Article in press. DOI 10.1002/fam.2685. ISSN 0308-0501.

[7] SARAZIN, J., BACHELET, P., BOURBIGOT, S. 2017. Fire behavior of simulated low voltage intumescent cables with and without electric current. Journal of Fire Sciences, 35(3), 179-194. ISSN 0734-9041.

[8] HAYNES, W., M. 2015. Handbook of chemistry and physics. 96th ed. Boca Raton: CRC Press, 2015. 2677 p. ISBN 978-148226096-0.

[9] MARTINKA, J. 2016. Cone calorimeter application on the comprehensive research of fire risk of selected organic polymers and combustible liquids: Habilitation. 1st ed. Bratislava: Slovak University of Technology in Bratislava, $192 \mathrm{p}$.

[10] CHEN, C., CHEN, J., ZHAO, X., SHI, C. 2018. Experimental investigation on combustion characteristics of steel cable for cable-stayed bridge. Journal of Thermal Analysis and Calorimetry, 134(3), 2317-2327. ISSN 1388-6150.

[11] BEJI, T., VERSTOCKT, S., ZAVALETA, P., MERCI, B. 2016. Flame Spread Monitoring and Estimation of the Heat Release Rate from a Cable Tray Fire Using Video Fire Analysis (VFA). Fire Technology, 52(3), 611-621. ISSN 0015-2684

[12] HU, L., ZHU, K., LU, Y., ZHANG, X. 2019. An experimental study on flame spread over electrical wire with high conductivity copper core and controlling heat transfer mechanism under sub-atmospheric pressures. International Journal of Thermal Sciences, 141(1), 141-149. ISSN 1290-0729.

[13] MORANDINI, F., SILVANI, X., DUPUY, J., SUSSET, A. 2018. Fire spread across a sloping fuel bed: Flame dynamics and heat transfers. Combustion and Flame, 190(1), 158-170. ISSN 0010-2180.

\section{ORCID}

Aleš Nečas

Jozef Martinka

Martina Hladová

Karol Balog
0000-0003-3626-7092

0000-0002-0060-5785

0000-0003-4281-9834

0000-0002-0804-8338 